\title{
Opening the Music Box
}

\section{Citation}

Rehding, Alexander. "Opening the Music Box." Journal of the Royal Musical Association 144, no. 1 (2019): 205-21.

\section{Permanent link}

http://nrs.harvard.edu/urn-3:HUL.InstRepos:42656643

\section{Terms of Use}

This article was downloaded from Harvard University's DASH repository, and is made available under the terms and conditions applicable to Open Access Policy Articles, as set forth at http:// nrs.harvard.edu/urn-3:HUL.InstRepos:dash.current.terms-of-use\#OAP

\section{Share Your Story}

The Harvard community has made this article openly available.

Please share how this access benefits you. Submit a story.

Accessibility 


\title{
Opening the Music Box
}

\author{
Alexander Rehding
}

Rebecca Cypess, Curious and Modern Inventions: Instrumental Music as Discovery in Galileo's Italy (Chicago: University of Chicago Press, 2016) ISBN: 9780226319445, Deirdre Loughridge, Haydn’s Sunrise, Beethoven's Shadow: Audiovisual Culture and the Emergence of Musical Romanticism (Chicago: University of Chicago Press, 2016) ISBN: 9780226337098, Thomas Patteson, Instruments for New Music: Sound Technology and Modernism (University of California Press, 2016) ISBN: 9780520288027.

THE SIMPSONS, the longest-running sitcom on television, have long made history. But they truly made music history in the episode "Lost our Lisa" from Season 9 (first aired in 1998). ${ }^{1}$ Lisa Simpson, the intellectual in the family, and her ne'er-do-well father Homer have broken into the "Springsonian Museum" at night and are exploring the Egyptian exhibition. They stop in front of an exhibit, the mysterious Orb of Isis, which anthropologists have studied for years without lifting its secret. Homer tries to get a closer look, but in climbing over the velvet rope that holds visitors at bay, he stumbles, and the rope poles hit the pedestal on which the sphere is placed. It falls to the floor, breaks open, and reveals itself as an ancient Egyptian music box. In a plinky timbre, and ever so slightly out of tune, it plays a short piece in two voices, transcribed in Figure 1. Lisa marvels: "And just think, we are the first people to hear its song in more than four thousand years. [...] The music we just heard might never be heard again." To which Homer replies, in a rare father-anddaughter bonding moment: "But it will always live on because we will never forget it." The solemnity of the scene is immediately dispelled when Homer begins to whistle a completely different tune-which Lisa identifies as the Old Spice song. Any remnant of the strange beauty of the Egyptian music in our memories is immediately wiped away by this new tune, which Homer and Lisa both sing lustily as they exit the museum, though not without setting off the alarm and getting chased out by dogs.

Figure 1: The music from the "Orb of Isis." (+ indicates a small deviation in intonation).

\footnotetext{
${ }^{1}$ A big shoutout here to Gina Rivera and Jonathan Kregor, who first encouraged me to give the Simpsons their scholarly due.
} 
This brilliant film sequence, barely two minutes long, sums up a lot that has been happening in musicology for the last few years. As part of a broader sonic turn, musicologists have started to examine musical instruments as historical sources. They have begun to liberate the sound-based knowledge that dwells inside the instruments, often under the banner of what came to be known as Critical Organology. ${ }^{2}$ Outside the cartoonish logic, there are few cases as clear-cut as the Simpson's ancient music box, in which the object itself houses both a form of musical notation and a performance of it, offering incontrovertible knowledge directly to our ears. ${ }^{3}$ In most cases, it is necessary to adjust the objectives of musicological investigation around this new type of source. At a time when the field of inquiry is more willing to venture outside the imaginary museum of musical works - Springsonian or otherwise - this is not beyond the realm of the imagination. ${ }^{4}$ But it does require changes, in some cases mere tweaks and in some others more fundamental configurations of our assumptions, especially as regards the centrality of scores and composed works-and this is where things get interesting.

In a world that takes musical instruments seriously, the parameter of timbre comes into its own. This poses particular challenges, since the category of timbre has forever evaded representation on the printed page — conventional music examples tend to be inadequate in capturing this most elusive dimension of sound. ${ }^{5}$ The "sonic turn" urges us to take seriously the media in which we communicate knowledge. In this spirit, it is worth pointing out that my earlier transcription of the music of Isis is intrinsically problematic, as it focuses exclusively on pitch and rhythm, as Western

2 See John Tresch and Emily Dolan, "Toward a New Organology: Instruments of Music and Science," Osiris 28, no. 1 (2013), 278-298, although they still used the Baconian moniker "New" at the time. The actual term "critical organology" goes back to Maria Sonevytsky, "The Accordion and Ethnic Whiteness: Toward a Critical Organology," The World of Music 50, no. 3 (2008), 101-118, and Eliot Bates. “The Social Lives of Musical Instruments.” Ethnomusicology 56, no. 3 (2012), 363-395. Critical Organology was put on the map after a roundtable at the 2013 AMS meeting, complete with ensuing controversy between organologies old and new, as documented in Jessica L. Wood's and Emily Dolan's position papers printed side-by-side, "Perspectives on Critical Organology," Newsletter of the American Musical Instruments Society 43 , no. 1 (2014), 14-16.

${ }^{3}$ W. Anthony Sheppard, "Puccini and the Music Boxes," This Journal 140, no. 1 (2015), 41-92, may be the only example that comes close.

${ }^{4}$ See Lydia Goehr, The Imaginary Museum of Musical Works (Oxford: Oxford University Press, 1992). For non-American readers, the "Springsonian museum" is the Simpsons' pun on the Smithsonian Institution in Washington, DC.

${ }^{5}$ See Emily Dolan and Alexander Rehding, The Oxford Handbook of Timbre (New York: Oxford University Press, forthcoming 2019). 
notation generally does, while ignoring microtonal deviations and relegating the timbral dimension to barebones descriptive terms. The poverty of my chosen term- "plinky"-illustrates dramatically the want of a robust critical terminology for timbral matters. At the same time, it is the most expedient way to convey the aural impression on the printed page in a way that would communicate-from musicologist to musicologist - those elements that our discipline have traditionally held to be essential about music. And that's precisely the point: Critical Organology promises to turn musicology inside out.

To understand the epistemological fallout, it is useful to turn briefly to Guido Adler, the Viennese founding father of the discipline, in whose shadow we have long labored. Back in 1885, in the foundational manifesto that laid out "scope, method, and goal" of the young discipline, Adler saw historical continuity right from the very earliest attempts at human music-making. In his vision, Adler effectively inserted a proto-musicologist right at the moment when Cro Magnon man first heard the sound of his own singing voice, discovering the pleasures behind the melodic patterns he was producing. The moment music emerges is also the moment musicological reflection must begin. The reason is a simple definitional issue: unless there's critical reflection, Adler argues, it cannot be properly called music. ${ }^{6}$ As he later specifies, however, and in deviation from this striking initial image, there are additional conditions in the modern world: a musical artwork must be written down; only then does music become wissenschaftsfähig, open to scientific reflection. ${ }^{7}$ And music, Adler explains categorically, is analyzed in terms of rhythms, tonal organization and relationship between individual voices, then instrumental forces and issues of performance. ${ }^{8}$

It may be useful to historicize this decision: Adler's focus on the elements of musical style was a scientific response to the proliferation of biographical work on composers in his own time. ${ }^{9}$ His wider framework takes the familiar production line of composer-score-performer as a starting point. The clear focus in this framework must always be on the act of compositional production; Adler separates strictly between creative production and recreative execution, a division of labor that

${ }^{6}$ Guido Adler, “Umfang, Methode und Ziel der Musikwissenschaft," Vierteljabrsschrift für Musikwissenschaft 1, no. 1 (1885), 5 [5-20].

7 Ibid., 6.

8 Ibid., 6-7.

${ }^{9}$ For an investiagation of Adler's scientific models, see Benjamin Breuer, "The Birth of Musicology from the Spirit of Evolution: Ernst Haeckel's Entwicklungslehre as Central Component of Guido Adler's Methodology for Musicology" Ph.D. Dissertation (University of Pittsburgh, 2012). 
may not be disturbed. Engagement by the performer is, at best, a complicating and meddlesome distraction, and at worst a lethal aberration:

There is one element of artistic production in which reproducing artists engaged creatively: in embellishments. These owe their progress to natural and unnatural stirrings, which grew out of bounds in the seventeenth and first half of the eighteenth centuries as parasitical vines whose tendrils threatened to suffocate the robust trunk. ${ }^{10}$

The arch-organic image of healthy and stable trunk vs. creepy, asphyxiating vines sets up an opposition between composers and performers as a kind of evil, albeit a necessary one, which must be held in check. In this framework, which is primarily interested in fixating musical texts by the means of paleography and philology for further academic study, the order in the production chain from composer to performer must not be disturbed. No wonder that Adler's famous taxonomical chart of musicology relegates organology to a subsidiary role, as the final pillar of the system, almost an afterthought. ${ }^{11}$ Instruments are seen as a mere endpoint, incapable of acting as a driving force. The real music history happens elsewhere.

Musicology has long fared well with this model. It has the advantage of being neat, clean, and relatively easy to handle. Almost a century after Adler, Carl Dahlhaus reaffirmed the centrality of musical structures as represented in the score, defending the constellation against other potential historiographies. ${ }^{12}$ And even more recently, Richard Taruskin makes a pragmatic case for limiting his monumental Oxford History of Western Music (2005) to notated music from the literary Western tradition. ${ }^{13}$ Their respective reasons, although coming from different parts of the music-political spectrum, are easy to comprehend. Looking back at the Simpsons' fleeting encounter with Egyptian music, quickly superseded by the catchy Old Spice tune, it is understandable why human memory makes a fickle storage device. To put it in the terms of modern information processing, for the

\footnotetext{
10 Adler, "Umfang," 6.

11 The full story is more complex, of course, and would include such other nineteenth-century institutions as (entirely silent) museums for musical instruments. I thank Emily Dolan for pointing this out to me.

${ }_{12}$ Carl Dahlhaus, Foundations of Music History, tr. Mary Whittall (Cambridge: Cambridge University Press, 1983), 39, and chs 9 and 10. Here again, the full story is more complex: Dahlhaus was fully aware of the shortcomings of the model of musicology of Adler's age, see 131.

${ }^{13}$ Richard Taruskin, The Oxford History of Western Music (New York: Oxford University Press, 2005), 1: xxiii.
} 
purposes of data retrieval and repeated access, few media offer the same platform stability as written sources.

But, as many commentators have observed, this model has considerable limitations. The stability of the text may not be the only thing that matters. If notes are a shorthand-effectively a "recipe" from composer to performer, with instructions to reproduce- they have focused on what is considered essential in the pursuit of this goal. But notes leave out a whole lot that may also be going on in the processes and institutions that constitute music. Scholars such as Christopher Small have shown that a conception of music in works displace conceptions of music as an event or as a process, with considerable consequences. ${ }^{14}$ The recent resurgence of interest in improvisation, virtuosity, and arrangements reaches beyond the limits of the work concept and goes where Adler's musicology feared to tread.

Where the score alone is wanting, the instrument may come to the fore as a key element, a medium that is no longer restricted to "mere" reproduction. Or, to return to Adler's image, a botanist might discover that the tendrils slung around the trunk are not an invasive species. They might thrive in symbiosis with the tree they surround. Perhaps the tree is even irrelevant. There are whole new ecosystems to be discovered. All we need are better tools to give us insight into how these musical ecosystems work.

\section{Turning the tradition inside-out}

Emily Dolan's astonishing book The Orchestral Revolution (2013) took the bull by the horns, and zoomed in right to the moment that has traditionally marked the point de perfection for music history in Adler's vein: the classical style, as epitomized by Haydn and the symphony. ${ }^{15}$ It is useful to dissect all the components, assumptions and conflations that are at play in this conception of music history, and to make this crystal-clear, perhaps overly so, we shall briefly turn to one of the more metaphysical thinkers in this tradition, the German musicologist Hans Heinrich Eggebrecht. ${ }^{16}$ His notion of "musical thinking" aimed to see through the compositions that make up music history, and

\footnotetext{
${ }^{14}$ Christopher Small, Musicking: The Meanings of Performing and Listening (Middletown, CT: Wesleyan University Press, 1998).

15 See Dahlhaus, Foundations, 156-158.

${ }^{16}$ Eggebrecht, it should be noted, was not without his critics. See for instance, the AMS roundtable discussion on Eggebrecht in Indianapolis 2010, http://www.ams-net.org/indianapolis/eggebrecht/. I am using his example here because it is more explicit than most others, to outline a general tendency that was more muted in most other quarters.
} 
to trace the underlying developments of creative musical thought through the succession of compositions. $^{17}$

While largely modeled on the music aesthetics of the generation that included both Arnold Schoenberg and Hans Pfitzner, Eggebrecht's model harks back to a quasi-Hegelian conception in which the forces of history and progress manifest themselves through the works of a few geniuses. For Eggebrecht, the procession of compositions that make up music history is a succession of "congealed" ${ }^{\prime 18}$ slices of history from which the state of musical thought can be determined. ${ }^{19}$ In this view, compositional work is underpinned by elemental creative forces_Eggebrecht's "musical thought" - that technically flow in continuous progress, but that remain largely inaccessible. They can only be read out of individual snapshots, cross-sections, as it were, as they manifest themselves in individual musical works - hence the curious image of congealed slices — which are somehow dictated to genius composers by the forces of history. This model ensures that Haydn and the symphony are joined by the hip. Or insert any other biological metaphor here-most other images will be more graphic. ${ }^{20}$

What is striking about Eggebrecht's model is his insistence on sounds, or in German Klänge, as the true motor of history. But for all his emphatically sonorous rhetoric, these sounds are strangely empty and abstract. Eggebrecht's sonorities remain muted, thought up in the creative imagination of composers and confined silently to the manuscript paper in front of them, in the strict succession from one great composer to another, as laid out in Adler's model decades earlier. Dolan carefully unravels these long-held assumptions. She reminds us that what astonished Haydn's audiences was not the symphony as such, with its stylistic hallmarks, formal requirements, and generic traditions emerging from it, as Adlerian music history teaches us. Instead, Haydn’s audiences were overwhelmed by the ravishing sound of the orchestra.

The best way to understand this maneuver is as a figure-background reversal: Dolan shows that Haydn's most stunning orchestral effects, such as the "Surprise" symphony, have relatively little to

\footnotetext{
${ }^{17}$ Hans Heinrich Eggebrecht, "Musikalisches und musiktheoretisches Denken,” in Frieder Zaminer, ed., Geschichte der Musiktheorie (Darmstadt: Wissenschaftliche Buchgesellschaft, 1985), 1: 57 [40-58].

18 Hans Heinrich Eggebrecht, "Musikalisches Denken,” Archiv für Musikwissenschaft, 32 no. 2 (1957), 230 [228-240].

${ }^{19}$ Eggebrecht, "Musikalisches und musiktheoretisches Denken," 58.

${ }^{20}$ Oswald Koller tried to bring Darwinian evolution and the principle of sexual selection to the field of music history by pairing up genres and styles with composers who gave birth to them. See his "Die Musik im Lichte der Darwin'schen Theorie," Jabrbuch der Musikbibliothek Peters 7 (1900), 35-50.
} 
do with genre and form of the symphony, but belong in the same category as his oratorios, above all the fabled "Representation of Chaos" that opens The Creation. Here, too, she admonishes, we have spent far too much time worrying about the enigmatic form of the movement, and paying too little attention to the revelatory handling of the orchestra.

The point de perfection that the founding fathers of our discipline chose for their historiographic model — along with the valorization of form, harmony, and music as an abstract, notated categorywas also a decisive turn away from timbre and orchestration as a factor deserving of serious academic consideration. To be sure, timbre had always proved an elusive quantity, as a vexed JeanJacques Rousseau found when he tried to define the term, then still spelled tymbre, for d'Alembert and Diderot's Encyclopédie. ${ }^{21}$ But various attempts had been made during the nineteenth century to capture this dimension in productive terms - most famously in Helmholtz's epochal Lehre von den Tonempfindungen (1863). ${ }^{22}$ To understand what exactly happened to Haydn in the hands of the generation of the discipline's founding fathers it is instructive to turn to Hugo Riemann's Katechismus der Orchestrierung, in which Haydn serves as a model. Not only that, Riemann's preferred pedagogy focuses on the orchestration of Haydn piano sonatas, turning the clichéd assumption that symphonies are nothing but sonatas for orchestra into a sounding reality. ${ }^{23}$

Riemann explains, entirely in line with the eighteenth century, that the body of string sounds was at the heart of the symphony orchestra, and formed the neutral background that articulated the musical structure. ${ }^{24}$ Against these normative string sounds, wind instruments and percussion were set to employ special effects, musical highlights of specific passages. Riemann's model serves above all to normalize Haydn: his method of handling the orchestra becomes the foil against which later composers, above all those in the post-Beethovenian line, are measured. What falls out of the

\footnotetext{
${ }^{21}$ See especially Dolan, Orchestral Revolution, ch. 2. See also Cornelia Fales, "Listening to Timbre during the French Enlightenment," in Caroline Traube and Serge Lacasse, ed., Proceedings of the 2005 Conference on Interdisciplinary Musicology (Montréal: Centre for Interdisciplinary Research in Music Media and Technology, 2005), 1-11. See https://www.researchgate.net/profile/Cornelia_Fales/publication/228619981_Listening_to_timbre_during_the_french _enlightenment/links/0046353a0c1db0719b000000/Listening-to-timbre-during-the-french-enlightenment.pdf.

22 See Benjamin Steege, Helmboltz and the Modern Listener (Cambridge: Cambridge University Press, 2012) and Julia Kursell, “Ohr und Instrument: Zu Hermann von Helmholtz’ physiologischer Grundlegung der Musiktheorie,” Habil. Diss. (Technische Universität Berlin, 2013).

${ }^{23}$ Of course, Riemann was hardly alone here. It is indicative of the wider focus on ideal forms-Hanslick's tönend bewegte Formen - for which instruments merely provided a material garb.

${ }^{24}$ Hugo Riemann, Katechismus der Orchestrierung (Anleitung zum Instrumentieren) (Berlin: Max Hesse, 1902), 5.
} 
picture entirely is a sense of how much labor went into the process of making Haydn's orchestration so thoroughly normative as to become eminently forgettable. It is this sense that Dolan is recreating in The Orchestral Revolution. It is the orchestra is emphatically the hero of the book-not Haydn, not the symphony - and Dolan's ambition is to re-sensitize us to the innovative force of the orchestra in eighteenth-century music.

And likewise, there is a second sense in which this is not a book about Haydn, but about "Haydn," that is, the version of the composer that became enshrined in musicological thinking and historiography. Dolan's book shows that all the critical components for the sound-centred exploration of music were in place in the late eighteenth century-Rousseau's definition of timbre for the authoritative Encyclopédie, an intrigue with the scientific (and not-so-scientific) facts of sound in relation to color epitomized by Père Castel's curious clavecin oculaire, plus a keen appreciation of the rousing sounds of the orchestra as documented widely in the press. But the nineteenth century, and we as a discipline, chose to abandon that path in favor of other concerns.

There are some obvious reasons why timbre fell out of favor in the nineteenth century as a topic of musicological discussion: as the analytical branches of the discipline developed robust models of certain technical aspects of music, above all harmony and form, and the technology of notation doubled up as a welcome shorthand in musical examples, capable of capturing what was considered the musical essence of full scores, orchestration and timbre fell by the wayside almost by necessity. But if notes can be understood as the atoms of music in the classical mechanics of our discipline, then the study of timbre ushers in a renewed focus on the subatomic particles; it ushers in a general theory of relativity.

\section{Synthesizers and other Writing-Down Systems}

In 1977 the French economist and political mover-and-shaker Jacques Attali wrote the little book that could. Noise (Bruits) proposed a different kind of music history that reckoned upwards from the underlying system of circulation, following four stages: Orality, Writing, Recording, Composing. ${ }^{25}$ Each mode of exchange brought forth its particular music. Even the very definition of music is under construction: in the first place there is nothing but noise-violent, unruly sound—which societal forces must first subjugate, separate, and domesticate into orderly music. The sacred

\footnotetext{
${ }^{25}$ Jacques Attali, Noise: The Political Economy of Music, tr. Brian Massumi, with an afterword by Susan McClary (Minnesota: University of Minneapolis Press, 1985).
} 
composer-score-performer axis describes nothing but one economic system of music, which needs to be historicized. From Attali's perspective, musicology in Adler's vein has focused firmly on the second stage, writing, practically at the exclusion of all else. While many of the aspects of Attali's book are discutable, as French academics like to demur, the approach to music history-from the material givens to the music produced-resonates strongly with the recent slew of books focusing on instruments as the key players in their musical ecologies. ${ }^{26}$

It might be helpful to translate Attali's four-stage economic approach into the technological language of German media theory, as each of Attali's stages effectively renegotiates the three principal functions that make up the medium: data selection, storage, and dissemination. ${ }^{27}$ It is not a stretch to think of Attali's musical ecosystems, the various systems of exchange, in terms of “discourse networks" in Sybille Krämer's extended definition:

There are not always data on the one hand, and then, on the other hand, the media that are concerned with the data. It is far more the case that media are the production sites of data. These production sites are discourse systems [Aufschreibesysteme], the networks of techniques and institutions that preprocess what will even be considered data in a given epoch. ${ }^{28}$

Within this more generalized model of media, it emerges that the division into composer and performer, the cornerstone of Adler's model of musicology, is nothing but an artifact of the score, specific to the exchange system of writing. Notation is, in a very literal sense, an Aufschreibesystem, a writing-down system, but it is also one in Krämer's broader sense: a production site of data that flourishes in (and that in turn brings forth) particular institutional and technological networks. By making the musical work repeatable, and moveable across time and space, by giving the musical conception manifest shape in writing and print, the medium of notation also brings about by necessity a division of labor between composer and performer. As W.J.T. Mitchell has pointed out, such a "telephone model" of media has a tendency to draw in sender and receiver of the message-

\footnotetext{
${ }^{26}$ For a critique of Attali, see Eric Drott, "Rereading Jacques Attali's Bruits," Critical Inquiry 41, no. 4 (2015), $721-756$.

${ }^{27}$ See especially Friedrich Kittler, Gramophone, Film, Typewriter, tr. Geoffrey Winthrop Young (Stanford, CA: Stanford University Press, 1999). The best introduction to Kittler's work remains Geoffrey Winthrop Young, Kittler and the Media (Cambridge: Polity, 2011).

28 Sybille Krämer, "The Cultural Techniques of Time Axis Manipulation: On Friedrich Kittler’s Conception of Media," Theory, Culture \& Society (2006), 97-98 [93-109].
} 
or indeed, as in this case, even to create these instances. ${ }^{29}$ But these elements are by no means natural, inevitable, or even strictly necessary.

If Attali has helped us understand that there are alternatives to the conventional system of exchange in writing, which has been the sole focus of traditional musicology, then critical organology may help us think through alternative systems of exchanges or discourse networks. Where Dolan's trailblazing book points us to the route not taken in the nineteenth century, laying out an alternative path for us that we can pick up if we so choose, Deirdre Loughridge's wonderfully creative Haydn's Sunrise, Beethoven's Shadow (2016) takes some of these strands further. Loughridge views the music of German romanticism from a distinct media-critical perspective. Crucially, she is not just interested in that strand of the tradition that would later become known as "absolute music"-but her catholic approach to the period includes Lieder, melodrama, and incidental music, as well as symphonies, operas, and oratorios. More importantly, she zooms in at an even closer level than Dolan: her protagonist is no longer the orchestra as a multi-headed music-making organism, but the special effects section, such as the string mutes in Haydn's orchestra that conjure up the effect of spatial distance. Her broader story is a counternarrative to the separation of the arts that long dominated the disciplinary discourse in its attempt to purify "the music itself." 30 She points instead to the myriad ways in which visual and aural media were mutually reinforcing. ${ }^{31}$ This audiovisual story, inevitably, has a distinct material bent. The world in which Loughridge takes us is a curiosity shop filled with the ephemera of intriguing looking devices from the nineteenth century, peepshow boxes, shadow puppets, microscopes—-media that primed listeners' ears for related sonic effects. ${ }^{32}$ No surprise that Haydn's blockbuster The Creation also plays a pivotal role here: Loughridge

${ }^{29}$ W.T.J. Mitchell, Image Science: Iconology, Visual Culture, and Media Aesthetics (Chicago: University of Chicago Press, 2015), 115.

${ }^{30}$ This is as good a place as any to point out the continued relevance of Gotthold Ephraim Lessing's Laocoon essay (1766), which divided the arts along the lines of space and time. Lessing did not cover music, which is why the essay has not received as much attention as it did in other fields. No surprise that German media theory has latched onto this tradition. See, for instance, Michael Franz, Wolfgang Schäffner, Bernhard Siegert, and Robert Stockhammer, eds., Electric Laokoon: Zeichen und Medien von der Lochkarte zur Grammatologie (Berlin: Akademie-Verlag, 2007).

31 Sound studies has had a complicated relationship with visual studies. See Jonathan Sterne's celebrated "audiovisual litany," in The Audible Past (Durham, NC: Duke University Press, 2003), ch. 1.

32 This category of objects was famously foregrounded in Jonathan Crary's Techniques of the Observer: On Vision and Modernity in the Nineteenth Century (Cambridge, MA: MIT Press, 1990), one of the foundation charters of Visual Culture/Visual Studies. 
is excellent at teasing out how large parts of the score, with its magical sound effects, contribute to a truly cinematic impression. Loughridge extends the notion of the instrument beyond the strictly musical, and shows how our discourse of Romanticism hinges precisely on the kinds of experiences that become possible thanks to those instrumental technologies.

Loughridge and Dolan hone in on the turn of the nineteenth century as a key turning point for a sound- and media-sensitive music history (one slightly earlier, the other slightly later). ${ }^{33}$ But there are various other moments in history when musical thought found itself at similar crossroads. A further turning point in our thinking about instruments and timbres occurred in the early twentieth century, not coincidentally dubbed the "second industrial revolution." This moment in history also roughly corresponds with Attali's third stage, Recording, at which the print monopoly was broken, and the circulation of sheet music was rapidly supplemented by an economy of recorded works-or, to use Walter Benjamin's influential (if slightly mistranslated) term, the "age of mechanical reproduction."34

Thomas Patteson's eye-and-ear-opening book Instruments for New Music explores the busy innovative activity during the Weimar Republic 1919-1933. ${ }^{35}$ The instruments in question are all electric, and many of them not musical instruments in a conventional sense. Patteson is particularly interested in machines that are used against the grain. In Patteson's book music emerges from all sorts of instruments that bypass the conventional composer-score-performer axis. The chapters are peopled with self-playing Welte-Mignon pianos, wavey lines scratched into the celluloid that turn into ethereal film music, and synthesizers creating otherworldly sounds. The fascination with these instruments and noisemakers is balanced by another wise decision: the composers and works that are being discussed are distinctly B-list (and, just to be sure, there is absolutely no shame in that). There is little danger that the great-composer model might overshadow the different historiography that is being attempted here. The stage is entirely given over to the world of the machine.

Patteson is eager to move this early chapter of electrified music out of the shadows, where it has languished as a mere prelude to the later Elektronische Musik of the 1950s and 60s, and to shine a spotlight on it instead as the first age of electronic music. But the bigger story that is woven into the

\footnotetext{
${ }^{33}$ Clifford Siskin and William Warner, eds., This is Enlightenment (Chicago: University of Chicago Press, 2010) redefine this key moment in history as a new approach to media and communication.

34 See Michael W. Jennings, tr., “The Work of Art in the Age of Its Technological Reproducibility [First Version],” Grey Room 39 (2010), 11-37.

35 University of California Press deserves praise for making this book available for free download. https://www.ucpress.edu/book/9780520288027/instruments-for-new-music.
} 
narrative at a deeper level is the ongoing search for new instrumental Aufschreibesysteme. After all, 1920s Germany is also the time for iconoclastic aesthetic programs, by such innovators as László Moholy-Nagy and Hans Heinz Stuckenschmidt, who both experimented with forms of sound, writing, and media, to reconfigure the creative act in line with (and in some cases against the grain of) the broadened capabilities of the new technologies.

Chapter by chapter Patteson enters deeper into a world in which the sound is further and further removed from the pregiven reservoir of notes that we are familiar with from most conventional acoustical instruments - and, for that matter, the dimensions of standard staff notation. The most radical departure into a new world, and into a new Aufschreibesystem, we encounter in Rudolf Pfenninger's and Oskar Fischinger's attempts to engrave the soundwave directly onto the celluloid of the film, and to create, in Thomas Y. Levin's memorable phrase, "tones from out of nowhere."36 Fischinger's system leaves behind the familiar indexicality of notes and plunges headfirst into the continuous oscillating warp and weft of the soundwave. The film soundtrack becomes both the canvas for a new kind of notation and the vibrant string of a self-performing instrument.

Who is performer, who is composer? These unanswerable questions are relatively irrelevant in this framework, which firmly places the object at its center. Patteson shares the delight of media archaeologist of getting closer to a sense of the meaning of machines by epistemologically "reverseengineering" them, as Jussi Parikka puts it. ${ }^{37}$ This approach seems particularly apt for the aesthetics of the Weimar Republic, with its suspicion of the excessive subjectivity of the Expressionism of earlier years. The Neue Sachlichkeit (New Objectivity) has at its core a love of Sachen-objects, or better yet: "things." Things have a habit of developing their own mystique. As Bill Brown points out, things are not fully known-that's the prerogative of objects, to be subjugated to the scrutiny of subjects-but "encountered." 38 And just as Carl Grossberg's eerie oil painting Vision: Steam Boiler with Bat (1928) is effectively a portrait that places a mechanical apparatus exactly where one would normally expect a human subject, so the real divas in Patteson's remarkable book are the machines.

\section{Sounds and Interfaces}

\footnotetext{
36 Thomas Y. Levin, “'Tones from out of Nowhere': Rudolf Pfenninger and the Archaeology of Synthetic Sound,” Grey Room 12 (2003), 32-79.

${ }^{37}$ Wolfgang Ernst, tr. Jussi Parikka, Digital Memory and the Archive (Minneapolis: University of Minnesota Press, 2013$), 55$. See also Jussi Parikka, What is Media Archeology? (Cambridge: Polity Press, 2012).

38 Bill Brown, “Thing Theory,” Critical Inquiry 28 (2001), 1-22.
} 
The possibility that sounds could be written out directly had long been known. The Italian Renaissance scientist Filippo Salviati described his discovery of the principle of sounding script:

Scraping a copper plate with an iron chisel to take out some spots in it, upon moving the chisel quick to and fro, amongst the many attritions or rubbings, I, more than once, heard it send forth a whistling noise or sound, and then looking upon the plate I espied a long row of small streaks, parallel to one another, and exactly equidistant. ${ }^{39}$

It was by accident, in the process of a menial task like cleaning, that Salviati discovered the connection between scraping sound of the chisel and the patterned trace on the plate. In fact, so basic is this observation that it is questionable if this discovery should really be attributed to him, or for that matter, if it really constitutes a discovery. There is every chance that others before him made the same experience. But the significant difference is that Salviati recorded his observation in Florence at the turn to the seventeenth century, right at the heart of the Scientific Revolution, when the relationship between knowledge and authority was fundamentally shaken up.

Salvati's observation that sound can be written down as discrete regular marks with spaces between them is not substantially different from its modern storage in digital media, with its successions of on/off impulses. Sounds have always had a digital existence-long preceding the computer age-insofar as sounds have always been writable as alternating marks and spaces, presences and absences, ones and zeroes. Thus Salvati's observation points, on the one hand, to the rise of empiricism and experimentalism in the first Scientific Revolution, and on the other, to the binary system of Leibniz, the culmination of mathesis universalis, that is, the idea that the entire world can be explained with numbers. Discussions of the principles of music in the early modern period habitually operated with numbers - the Pythagorean heritage, which we have largely forgotten, as notes, not tones, became the chief object of musical reflection, was alive and kicking then. In the hands of Salvati and his brethren at the humanistic accademie and camerate all over Italy, this ancient knowledge was reconfigured into scientific insights. It is no exaggeration to say that Salvati's chisel was as much as scientific instrument as it acted as a makeshift musical instrument: in producing sounds it generated knowledge about music.

\footnotetext{
${ }^{39}$ Cited in H. F. Cohen, "Galileo Galilei," in Paolo Gozza, ed., Number to Sound: The Musical Way to the Scientific Revolution (Dordrecht: Kluwer, 2000), 222 [219-232] (spelling updated).
} 
That the term "instrument" is used both for scientific experimentation and for musical production is not an accident, as Rebecca Cypess explores in beautiful study Curious and Modern Inventions. She explores instrumental music of the early modern period for its scientific implications. Cypess's prompt for this investigation is the realization by historians of science that the Scientific Revolution was, first and foremost, a revolution in the specific significance with which instruments and experimentation were imbued in the formation of new knowledge. She sets out to show how music, and especially the instrumental works of Biagio Marini and his contemporaries-Giovanni Gabrieli, Salamone Rossi, Dario Castello, and Carlo Farina-formed an integral part of this new way of thinking.

The emphasis on instrumental music is a welcome counterpoint to the long-standing interest in the vocal music of that period. Cypess multilayered approach gets to the question of how musical instruments resembled scientific instruments in a somewhat roundabout fashion. She aims to tease out relevant information about the use of instruments by focusing on the composed works by Renaissance composers-cum-performers. As she contends right at the outset, written score materials constitute the best written historical record and therefore weigh heavily as evidence in her inquiry. This approach, which is essentially in line with traditional historical method, is a justifiable decision. But the displacement of the instrument, as the object for which a set of musical pieces are composed, also poses something of a methodological limitation: we can only get at the instrument obliquely, that is, by tracing it through the artistic creations of composers. When Cypess brings the spirit of the scientific revolution to bear on these musical compositions, as a consequence, the connections are made primarily at the suggestive level of analogy. In a series of historically sensitive vignettes, she invites us to hear Frescobaldi's toccatas in light of the newly invented clocks, and points to parallels between Salamone Rossi's trio sonatas and discourses of affect in contemporary portraiture. Musical instruments in Cypess's story remain a vehicle for artistic reflection on the rapid changes of early modern thought, while their participation in scientific discoveries is mediated through a handful of performers-turned-researchers whose findings are expressed artistically in compositions.

Her story complements and complicates the perhaps more familiar narrative of those Renaissance musician-scientists, such as Nicola Vicentino and Vincenzo Galilei (Galileo's father), for whom composition, performance, and instrument-building was a way to demonstrate certain 
underlying principles of music. ${ }^{40}$ What makes those figures particularly useful in this context is their ability to create incisive moments in music that outline a problem to be solved-in this case, the necessity for temperament. ${ }^{41}$ Galilei included in his treatises an ingenious composed demonstration of impossible enharmonic relations, reproduced in Figure 2, that highlights incisively the conflict between horizontal and vertical dimensions in multi-voiced music, showing that without temperament music would split at the seams. ${ }^{42}$ Crucially, the lute, Galilei's principal instrument, had traditionally been tuned in a pragmatic version of what came to be called equal temperamentwhich also turns out to be the solution that Western music writ large eventually came to adopt for this problem. ${ }^{43}$ Vicentino tried to solve a similar problem by creating new instruments, the archicembalo and the archiorgano, that broadened the pitch range of modern music considerably to accommodate the fine-tuned variety of melody and harmony. Daniel Walden has shown in detail how the performance on the archicembalo guided his hand, quite literally, in exploring the new microtonal world that his instrument had unlocked. ${ }^{44}$

\section{Figure 2}

\footnotetext{
${ }^{40}$ David Creese draws attention to the Aristotelian difference between apodeixis (proof) and epideixis (demonstration) in the use of musical instruments in scientific settings. While he focuses on ancient science, the methodological reflection provides food for thought extending far beyond its historical period. See his "Instruments and Empiricism in Aristoxenus' Elementa harmonica," in Carl A. Huffman, ed., Aristoxenus of Tarentum: Texts and Discussions (New Brunswick, NJ: Transaction Publishers, 2012), 29-63.

${ }^{41}$ Gioseffo Zarlino, Galilei's former teacher and the principal authority of music at the time, had made this problem relevant with his emphatic promotion of just thirds (5:4 and 6:5). Vicentino's and Galiei's proposed solutions can be regarded as representing opposite extremes. The classic on tuning systems remains Mark Lindley, Lutes, Viols,
} Temperament (Cambridge: Cambridge University Press, 1984).

42 See Daniel Chua, "Vincenzo Galilei, Modernity, and the Division of Nature," in Suzannah Clark and Alexander Rehding, eds., Music Theory and Natural Order from the Renaissance to the Early Twentieth Century (Cambridge: Cambridge University Press, 2001), 1-17. My “Instruments of Music Theory,” Music Theory Online 22.4 (2016)

<http://mtosmt.org/issues/mto.16.22.4/mto.16.22.4.rehding.html>, examines Vicentino's archicembalo. See also Brandon Konoval, "Pythagorean Pipe Dreams? Vincenzo Galilei, Marin Mersenne, and the Pneumatic Mysteries of the Pipe Organ," Perspectives on Science 26 no. 1 (2018): 1-51.

43 See David Dolata, Meantone Temperaments on Lutes and Viols (Bloomington: Indiana University Press, 2017) complicates a story that is often told all too simply.

${ }^{44}$ Daniel Walden, "Daniele Barbaro, Nicola Vicentino, and Vetruvian Music Theory in Sixteenth Century Italy" in Frédérique Lemerle, Vasco Zara, Pierre Caye, Laura Moretti, eds, Daniele Barbaro 1514-1570: Vénitien, patrician, humaniste (Turnhout: Brepols, 2018), 373-390. 
Vincenzo Galilei composes an impossible musical scenario in which melodies clash enharmonically in a complex contrapuntal framework.

Vicentino's archicembalo with its complicated double and multiply subdivided keyboard makes a passing appearance in Roger Moseley's breathtakingly original Keys to Play, as an example of an interface in music-making. ${ }^{45}$ As interfaces, keyboards are the connectors between the performer's fingers and the instrument, covering the haptic input into musical output, transducing kinetic energy into mechanical soundwaves. In this, they function as a gateway from one world to another. But, crucially, they can only convert certain kinds of energy, they allow only certain kinds of data to pass. Interfaces thus impose order and exert control; they set the rules and police the exchange flow. This is why it's useful to think of interfaces as bandwidth filters that enable or enhance certain kinds of engagements, while inhibiting others. For instance, out of the whole range of the pitch continuum, the keyboard can only accurately produce a limited number - typically twelve, but in the case of the archicembalo thirty-one (plus a few extra). ${ }^{46}$

Perhaps the most powerful demonstration the power of the interface is Brian Eno and Peter Chilver's iPhone app Bloom (2008), which effectively converts the screen of the phone into a covert diatonic keyboard over several octaves. The fascination with this app is largely based on the fact that the user (performer/composer) is unaware that the continuous area of the screen is subdivided into a keyboard of discrete pitch areas. This invisible keyboard cuts across the width of the screen, its $x$ axis, while the $y$-axis has no effect on pitch production. The performer plays around by tapping freely anywhere on the two-dimensional area of the screen, and delights in the colorful circles that ripple around the point of touch and intersect with others, as sounds are being produced and repeated in slowly fading melodic loops, created by an effortless touch. ${ }^{47}$ In this way slowly disappearing compositions of considerable complexity are created at the drop of a hat, forever available at the tip of one's finger. But the musical topography of the app work in very different ways from its visual counterpart: the restriction to a simple diatonic collection ensures that virtually any combination of pitches, successive or simultaneous, sounds relatively pleasing. While the

\footnotetext{
45 This book, too, has remarkably been made available on open access as a free download. https://www.ucpress.edu/book/9780520291249/keys-to-play

46 Vicentino's theoretical model requires thirty-one divisions of the octave, but his keyboard offers thirty-six.

47 On this topic, see also the JAMS colloquy "Discrete/Continuous: Music and Media After Kittler," especially Sybille Krämer, "Flattening as Cultural Technique: Epistemic and Aesthetic Functions of Inscribed Surfaces," Journal of the American Musicological Society 70, no. 1 (2017), 239-245.
} 
performers seem unconstrained by any rules and free to compose wherever their finger takes them, the invisible interface puts a tight grip on the control between input and output.

Moseley's book falls outside of the scope of this article, and this may be a blessing, simply because it's hard to do justice to the sheer brilliance of Keys to Play within the limited space of this review. But it is so important to the field of Critical Organology that it must be mentioned here. Put simply, Keys to Play does in the field of music studies what Bernhard Siegert's Passage des Digitalen, the still-untranslated bible in that field, did for German media studies. ${ }^{48}$ (Insofar as it is possible to summarize that book, it is best described as an archaeology of one and zero.) Moseley has read absolutely everything from pre-Socratic philosophers to Vilém Flusser and Cornelia Vismann, there is no concept in this wide-ranging book that is not mulled over from a number of different perspectives, each with an impressive bibliographic apparatus that one is tempted to call encyclopedic. The book flits effortlessly from chess boards to piano keyboards and typewriters to video games, from ars combinatoria to musical dice games and thence to partimenti and cognitive studies of improvisation, and back again.

Like Siegert and Krämer, Moseley's allegiance is to Cultural Techniques (Kulturtechniken)—the branch of post-Kittlerian media theory that adds a breath of humanism over Kittler's cheerful technological determinism. Cultural Techniques seek to carve out a space for human activity within the world of the machine. Moseley's chief interest lies in how we operate machines when we play music, however conceived, how we interact with the instruments we play (and when they, in turn, play us). In Moseley's hands, the notion of the instrument is further deconstructed into something more akin to Hermann Hesse's mysteriously compelling glass bead game, a system of rules that may or may not have a material component. But it is the playing body, exerting its freedom and reacting to constraints within these rules of the game, that is the central character in this extended investigation. In play, the body/machine performs such tasks as are conventionally subdivided into performance and composition—as well as, crucially, its hybrid improvisation.

The focus on the critical role of the interface is well taken. The relationship between keyboard and music is so close as to effectively be metonymic. ${ }^{49}$ This obvious interconnection often obscures the deeper role the interface takes on in converting one form of data into another, and one medium

\footnotetext{
${ }^{48}$ Bernhard Siegert, Passage des Digitalen: Zeichenpraktiken der neuzeitlichen Wissenschaft 1500-1900 (Berlin: Brinkmann und Bose, 2003).

${ }^{49}$ Emily Dolan, “Toward a musicology of interfaces.” Keyboard Perspectives 5 (2012), 1-13.
} 
into another. At the piano keyboard, the interface is the watershed between the unfathomable complexity of numbers and ratios and the sensory world of tones, intervals, and chords. The interface operates at precisely the location where we pass from numbers to sound, from one realm to the next - a gateway that is unlocked by a simple touch. With this musicology of the interface, Moseley and Dolan, each in their own ways, find a way to shine a light on the subatomic particles of music, to examine what goes on beneath the sounding surface.

\section{Notes and Tones}

Critical organology proposes a musicology that bypasses the notes and erects a foundation on tones. It moves away from the productive/reproductive axis of music, crystallized in the silent composerscore-performer model, and assigns epistemic value instead to the production of sound. This is the reason critical organology and sound studies are natural allies, united in the material basis with which they start, even though the wider outlook of each field may be cast in different directions. The different studies show that giving up on the stability associated with the institution of the score doesn't mean to build a foundation on sand.

To be sure, there is a certain noisiness in the proliferation of approaches. Perhaps the most important consequence is the relative disregard of chronological order. This is one of the warnings Dahlhaus and others issued years ago: if the discipline jettisons its focus on the act of composition, if it treats the artwork as existing in its own time, brought into existence each time it is performed, then all the odds are off for chronologies: Bach's St Matthew Passion become an object in the nineteenth century, Mahler's symphonies peak in the mid-twentieth century. ${ }^{50}$ Moseley's and Dolan's transhistorical work on interfaces show the virtuosic version of the undisciplined chaos that Dahlhaus so feared. The structural parallelisms of the technologies they investigate open up vistas into various temporal dimensions at the same time. There is, in fact, method behind the madness: the comparison of how the same mechanism operates in different contexts allows deeper insights into the changing epistemic status of these technologies.

Media historians are particularly fond of the principle of recursion as a historiography. ${ }^{51}$ Originally a term taken from computer science, recursion features in these histories as a mise-enabyme, a recurrence of the same at different levels. The German media archeologist Wolfgang Ernst

\footnotetext{
${ }^{50}$ Dahlhaus, Foundations, 39.

51 See Ana Ofak and Philipp von Hilgers, eds., Rekursionen: Von Faltungen des Wissens (Berlin: Wilhelm Fink, 2009).
} 
has taken this discontinuous history to its extreme with his startling claim that the sounds of an ancient lyre (or, to return to the initial vignette, a four-thousand-year-old Egyptian music box) are identical, no matter whether it was plucked several millennia ago or whether we do the same today. In recreating the exact same sound-shaping time in the most literal of senses-Ernst makes the provocative claim that these instruments, considered from the perspective of media archaeology, allow us to "actually leap back into that time." 52 Instruments, sound makers, become veritable time machines: the experience of the sound of music is ecstatic, a momentary suspension of historical time. ${ }^{53}$ This is the principle of recursion taken to its ultimate conclusion. Ernst's claim may be true on a strictly physical basis, but it is difficult to make the case how this insight would be meaningful as soon as we get beyond the molecular level. ${ }^{54}$ In the final analysis, Ernst's brand of media archaeology turns into chronocriticism. ${ }^{55}$ Whether Critical Organology will want to follow him there, or whether this is where the two might part ways, is an open question.

Treating musical instruments as epistemic things, as material objects, that can in the right circumstances issue forth new musical knowledge may not always be as straightforward as Lisa Simpson's mysterious and mythical "Orb of Isis," which produced sounding evidence of ancient Egyptian music. The actual quest to rediscover the musical secrets of Egypt can best serve as a cautionary tale showing up some of the pitfalls in this approach. ${ }^{56}$ But as our discipline changes, and as the dogged focus on the composer-score-performer axis fades more and more as a distant memory of a past dogma, Critical Organology can lead the way to new and undreamed-of shores. By acknowledging the vital role of media, of interfaces, more broadly conceived than just writing in notes, we can move to a more flexible paradigm within which all kinds of music can be investigated fruitfully. By reconfiguring the relationship between sound production and reproduction, instead of just composition and performance, critical organology can open up the discipline to innovative approaches. By focusing our eyes and ears on musical instruments, we can crack them open, like Lisa's Orb of Isis, to reveal the secrets of music in previously unheard-of ways.

\footnotetext{
52 Wolfgang Ernst, Im Medium erklingt die Zeit (Berlin: Kadmos, 2015), 218.

${ }^{53}$ Ibid., 196.

54 In Ernst's defense, he clearly excludes music, when defined "as an artform with a cultural semantics," from the domain of media archaeology. Media archaeology is only interested in the "techno-acoustical framework of sound and the implicit knowledge contained therein." See ibid., 183.

55 Ernst tends to call his work zeitkritisch, that is, "time-critical." I prefer Evander Price's term "chronocritical."

${ }^{56}$ See my "Music-Historical Egyptomania 1550-1900," Journal of the History of Ideas 75, no. 4 (2014), 545-580.
} 